\title{
Preneoplastic Lesions In Kidney And Carcinogenesis By Non-Genotoxic Compounds
}

\author{
D. R. Dietrich and T. Rasonyi \\ Institute of Toxicology, Swiss Federal Institute of Technology and University of \\ Zurich, Schorenstr. 16, CH-8603 Schwerzenbach.
}

Carcinogenesis is known to be a multistep process which involves two or more genetic events and requires cell proliferation (Pitot 1986; Barrett and Wiseman 1987; Farber and Sarma 1987; Knudson 1987; Cerutti 1988; Lutz 1990). The genetic events can result from point mutations, chromosomal rearrangements (Croce and Klein 1990), insertions or deletions of genes, and gene amplification. Cell replication is required to convert DNA damage to mutations, irrespective of whether this damage is occurring spontaneously or induced by DNA damaging (genotoxic) compounds. Spontaneous mutations are assumed to stem from spontaneous genetic events such as: depurination and deamination of DNA, formation of covalent DNA adducts by physiological reactive cellular constituents, DNA damage by oxygen free radicals produced in cellular metabolism, errors in DNA replication (Locb 1989). Normally the cell has the possibility to either repair the damaged DNA, or, if the damage is irrepairable, to destroy itself via tumor suppressor gene product (e.g. p53) mediated apoptosis (Lane 1993). Abrogated DNA repair or apoptosis of damaged cells in conjunction with a cell proliferative stimulus can lead to the formation of clusters of mutated cells and clonal expansion. Continued enhanced proliferation and expansion of such clones increases the probability of additional genetic events within these populations (Knudson 1987) thus providing a basis for the formation of preneoplastic lesions and progression to veritable tumors (Swenberg et al. 1987; Dietrich and Swenberg 1991b). Although the sequence of events described above appears reasonable, little direct evidence has been put forward so far. However, some corroboration is provided by the observation that control animals from strains of laboratory rodents present with an appreciable incidence of spontaneous preneoplastic lesions and tumors (Dietrich and Swenberg 1991b). The incidence of spontaneous tumors varies greatly from tissue to tissue, strain to strain, sex to sex. and species to species (Swenberg and Short 1987).

Non-genotoxic compounds by definition do not induce DNA damage themselves. However, non-genotoxic carcinogens can induce enhanced cell proliferation and thus contribute to the fixation of spontaneous mutations as well as to the formation and progression of preneoplastic and neoplastic lesions. Similarly, non-genotoxic carcinogens could abrogate removal of damaged cells via inhibition of the apoptotic processes and, in conjunction with a simultaneously occurring proliferative stimulus. could promote formation of preneoplastic and neoplastic lesions. Indeed, a commonly observed feature of non-genotoxic compounds tested at high concentrations in carcinogenicity bioassays is the concurrent cytotoxicity and/or cell proliferation along with hyperplasia in the tissues that finally develop tumors.

It is the aim of this short overview to delineate the mechanisms by which nongenotoxic renal carcinogens induce the formation of preneoplastic and neoplastic lesions. In the first part, the possibly best studied mechanism involved in the chemically (e.g. d-limonene, unleaded gasoline) induced renal disease known as 
$\alpha 2 \mu$-globulin nephropathy and subsequently increased cell proliferation and carcinogenesis will be reviewed. In the second part, the cytotoxicity and possible apoptosis inhibitive effect of nitrilotriacetic acid (NTA) will be discussed, while in the third some of the newest findings regarding the induction of renal tumors by the mycotoxin ochratoxin A will be presented. In the final part all of the above mechanisms will be discussed with regard to their importance in generating preneoplastic and neoplastic lesions in the kidney of rodents and the implications thereof for human cancer risk assessment. In addition, some emphasis will be laid on the comparison of rodent renal lesions with renal tumor types observed in humans.

\section{Chemically induced $\alpha 2 \mu$-globulin nephropathy and carcinogenesis}

There is an ever growing list of chemicals that induce a male rat-specific renal disease known as $\alpha 2 \mu$-globulin nephropathy. Neither female rats nor either sex of mice, guinea pigs, dogs, or monkeys developed this renal disease upon exposure to these chemicals (Dietrich 1994). Chronic exposure to a number of the $\alpha 2 \mu$-globulin nephropathy-inducing agents resulted in a low but significant incidence of renal tumors in male rats, but not female rats, either sex of mice, or male NBR rats deficient for the male rat specific $\alpha 2 \mu$-globulin (Dietrich and Swenberg 1991a; Dietrich and Swenberg 1991c).

$\alpha 2 \mu$-Globulin is synthesized by the male rat liver, except in NBR rats, at the onset of puberty and excreted in great amounts via the urine. Approximately half of this protein is reabsorbed by the proximal tubules of the renal cortex and enzymatically hydrolized to amino acids and peptides via lysosomal digestion. Possibly due to the relatively high resistance of $\alpha 2 \mu$-globulin toward catabolism, this protein has a natural tendency to accumulate in the P2 segment of the proximal tubules. Nongenotoxic chemicals e.g. d-limonene, unleaded gasoline, trimethylpentane, isophorone, or 1,4 dichlorobenzene and/or their metabolites have been shown to reversibly bind to $\alpha 2 \mu$-globulin. This reversible binding of chemicals is thought to alter the proteins digestibility within the lysosomes (Rivera Torres et al. 1989; Borghoff et al. 1990), leading to an exacerbated accumulation of protein-chemical complex in the lysosomes and to increased cell necrosis within the P2 segment. The currently most plausible, however so far unproven and also most disputed hypothesis, explaining the observed increased cell necrosis, is that autolytic cytotoxicity may result from lysosomal dysfunction, leakage of lysosomal enzymes into the cytosol, and decreased membrane availability and turnover (Short et al. 1989). Male rats treated with d-limonene, PS-6 unleaded gasoline or trimethylpentane were shown to compensate for the enhanced loss of proximal cells by increasing the rate of cell proliferation in the $\mathrm{P} 2$ segment. This increase in cell proliferation exhibited a dose response (Short et al. 1989) and was found to remain sustained, in the case of chronic d-limonene exposure, at 4-5 fold the rate found in unexposed rats (Dietrich and Swenberg 1991c).

Given the observation that non-genotoxic chemicals increase cell turnover and that the assumption holds true that chronically exacerbated cell turnover can promote the formation of spontaneously mutated cells, one would expect to find tubules and hyperplastic nodules containing phenotypically altered cells, i.e. preneoplastic lesions (Dietrich and Swenberg 1991b), already after a relatively short time (4-12 months) of exposure to these non-genotoxic chemicals. The latter assumption was corroborated 
in an initation-promotion experiment (Dietrich and Swenberg 1991c). This study demonstrated a fairly high number of preneoplastic lesions in kidneys of rats treated with the non-genotoxic promoting agent, dmimonene, already following 30 weeks of promotion (Table 1).

Table 1. Prencoplastic lesions observed in kitneys of male F3A4 rats of an initation. promotion experiment (Dietrich and Swenberg 1991c), comprised of a 2 week initiation with the DNA-alkylating agent N-ethyl-N-hydroxyethylnitrosamine (EHEN) and a 30 reck promotion with d-limonene. The number of preneoplastic lesions are expressed as the total number of lesions per treatment group and the number of lesions per animal. Nomenclature of preneoplastic lesions taken from (Dietrich and Swenterg 19916); AT: atypical tubule, AH: atypical hyperplasia.

\begin{tabular}{lccccc}
\hline Compound & Tolal AT & AThah & TotalAH & AHtrah & ATLAH \\
EHEN + diet & 469 & $15.6 \pm 1.5$ & 37 & $1.2 \pm 1.5$ & 13 \\
EHEN + d-limonene & 2015 & $65.0 \pm 3.4$ & 482 & $15.5 \pm 1.5$ & 4 \\
diet + d-limonene & 330 & $10.7 \pm 1.3$ & 13 & $0.4 \pm 0.1$ & 25 \\
Controldiet & 103 & $3.3 \pm 0.7$ & 0 & $0.0 \pm 0.0$ & .
\end{tabular}

This study also demonstrated the importance of cell proliferation in fixing DNA damage to mutations and progression of mutated cells to preneoplastic lesions. Indeed, the number of atypical tubules was 4-5 fold higher in the rats initiated with $\mathrm{N}$-ethyl-N-hydroxyethylnitrosamine (EHEN) and promoted with d-limonene than in rats treated with the initiating agent only. This factor $4-5$ corresponds quite nicely with the observed $4-5$ fold increase in proximal epithelial cell proliferation induced by d-limonene treatment. Although the total number of preneoplastic lesions found in rats treated with d-limonene only is distinctly lower than in rats treated with EHEN or EHEN and d-limonene, the three-fold and more than 13-fold higher number of atypical tubules and atypical hyperplasias in d-limonene promoted rats than in the corresponding control underlines the previous assumption that a higher number of spontaneous mutations can be fixed via enhanced cell tumover (Table 1). This observation, however, would also suggest that the incidence of these preneoplastic lesions is dependent on the rate of cell turnover. A dose dependent increase of atypical hyperplasias was indeed reported by Short et al. (1989) in male rats promoted with different concentrations of unleaded gasoline for 65 weeks.

As stated earlier, enhanced cell proliferation also appears to drive the progression from early preneoplastic lesions to veritable tumors possibly via additional mutational events. If these additional mutational events occur spontaneously i.e. via an endogenous mechanism, one would expect that preneoplastic lesions would progress to tumors only very slowly, despite an enhanced proliferative stimulus fayoring fixation of these rare spontaneous mutations. This concept may be visualized by naively calculating how many atypical tubules it takes to produce one atypical hyperplasia. As demonstrated in Table 1, it takes more than 103 atypical tubules for the formation of even one atypical hyperplasia in control animals, while the proliferative stimulus provided by d-limonene exposure reduced this number already to approximately 25 . Contrarily, genotoxic compounds characteristically induce DNA damage themselves and thus provide a strong basis for mutations, and in conjunction with a proliferative stimulus, favor the formation of fast growing preneoplastic lesions, as indicated by the fact that it takes only 4 atypical tubules for the formation of one atypical hyperplasia (Table 1). It is indeed observed that renal 
tumors induced by genotoxic compounds appear very early and in high incidence following treatment, in the case of EHEN initiation and d-limonene promotion already after 32 weeks (Dietrich and Swenberg 1991c), whereas renal tumors induced by non-genotoxic chemicals via the $\alpha 2 \mu$-globulin mechanism appear very late in the life of the exposed rats and at relatively low incidence (Dietrich 1994).

\section{NaNTA (nitrilotriacetate trisodium salt)}

Chronic administration of high concentrations ( $2 \%$ in the diet) of NaNTA have been shown to induce sustained cytotoxicity, preneoplastic lesions and tumors $(17 \%$ incidence) in the convoluted proximal tubule epithelial cells (PTEC) in either sex of mice and rats (Anderson et al. 1985). Acute and chronic dietary administration of NaNTA induces severe vacuolization and necrosis of the PTEC and proteinaceous casts at the cortico-medullary junction, followed by enhanced regenerative proliferation of PTEC. The mechanism by which cytotoxicity is induced is not entirely clear to date, however NTA, which is not metabolized in the mammalian system, is assumed to induce a redistribution of systemic zinc, leading to an increased resorption of zinc in the PTEC of the kidney (Anderson 1981). Both the acute (PTEC vacuolization) and the subchronic (PTEC vacuolization, necrosis and proliferation) nephrotoxicity were demonstrated to follow a dose response when the NTA-mediated intracellular zinc concentration was defined as the dose. Vacuolization appears to be the result of a change in cytoskeletal structure caused by micromolar concentrations of zinc which appear to alter the actin filaments. At higher zinc concentrations $(\geq 50 \mu \mathrm{M})$ intercellular junctions as well as the intracellular actin filament and microtubular organization are affected to such an extent that the celis undergo necrosis (Mills et al. 1992). In view of the NTA/Zn mediated necrosis it is expected that the PTEC regenerate in order to maintain renal function. Based on the observation that hyperplastic nodules were present following subchronic and chronic oral administration of NTA (Alden and Kanerva 1982), it was assumed that the chronic insult of NTA would also exert an enhanced proliferative effect on the PTEC. However, as no cell proliferation studies have been carried out it is not a priori possible to assume that $i$ ) enhanced cell proliferation takes place, and $i i$ ) cell proliferation is increased to such an extent that a higher number of spontaneous mutations are fixed and propagated to preneoplastic lesions. Indeed, despite the consideration that vacuolization of PTEC is classically considered a degenerative change and was observed on average in more than $50 \%$ of the convoluted tubules of NTA treated animals, actual granular degeneration and necrosis of PTEC was observed only in a small number of treated rats i.e. the most severely affected animals (Alden et al. 1981). This observation suggests that chronically enhanced cell proliferation may not be at all involved in the generation of preneoplastic lesions. If, however, the latter assumption holds true, one must ask which "non-genotoxic" mechanism(s) could be responsible for the genetic changes and cellular transformations preceding overt preneoplastic lesions. One such pathway, although yet unproven and therefore purely hypothetical, may be that normally occurring apoptosis of renal epithelial cells could be abrogated and in conjunction with the observed slightly enhanced cell regeneration (wound healing) could lead to the survival and propagation of epithelial cells with "altered or damaged" DNA. Wound healing per se was observed earlier to provide a provisional matrix advantageous to the growth of transformed cells (Stevens and Jones 1990), thus corroborating the 
latter assumption. Abrogated apoptosis by micromolar concentrations of zinc has been reported in chronic lymphatic leukemia cells and in glucocorticoid hormone exposed thymocytes (Martin and Cotter 1994). Two mechanisms are proposed by which zinc can abrogate apoptosis, namely that zinc could block calcium channels (Busselberg et al. 1990) and thus prevent calcium influx into the cells needed to activate calcium-dependent endonucleases and transglutaminases (Martin et al. 1994), or that zinc can inhibit the calcium-dependent endonucleases, therefore preventing the breakdown of DNA predominantly observed to be associated with apoptosis (Peitsch et al. 1994). If indeed apoptosis is inhibited, spontaneously occurring irrepairable DNA damage could persist and provide a source for an ever increasing number of transformed cells. It is important to emphasize here that from a genetic viewpoint the spontaneous DNA damage once fixed is considered irreversible. However, the survival of such genetically altered cells is highly dependent on the efficacy and presence of the mechanisms that regulate cell homeostasis such as apoptosis. This means that normal cells neighboring altered PTEC could recognize the altered state and induce apoptosis of the altered cell via cell-cell signalling. Consequently the organ should have the means to dispose of preneoplastic lesions via apoptosis, which is also indicated by the fact that not all preneoplastic lesions progress to veritable tumors (Dietrich and Swenberg 1991b). However, not all preneoplastic lesions may be susceptible to apoptosis, whether selfinduced or induced by the surrounding normal tissue, susceptibility to apoptosis may largely depend on the nature and/or degree of cellular transformation of the respective preneoplastic lesion (Fig. 1).

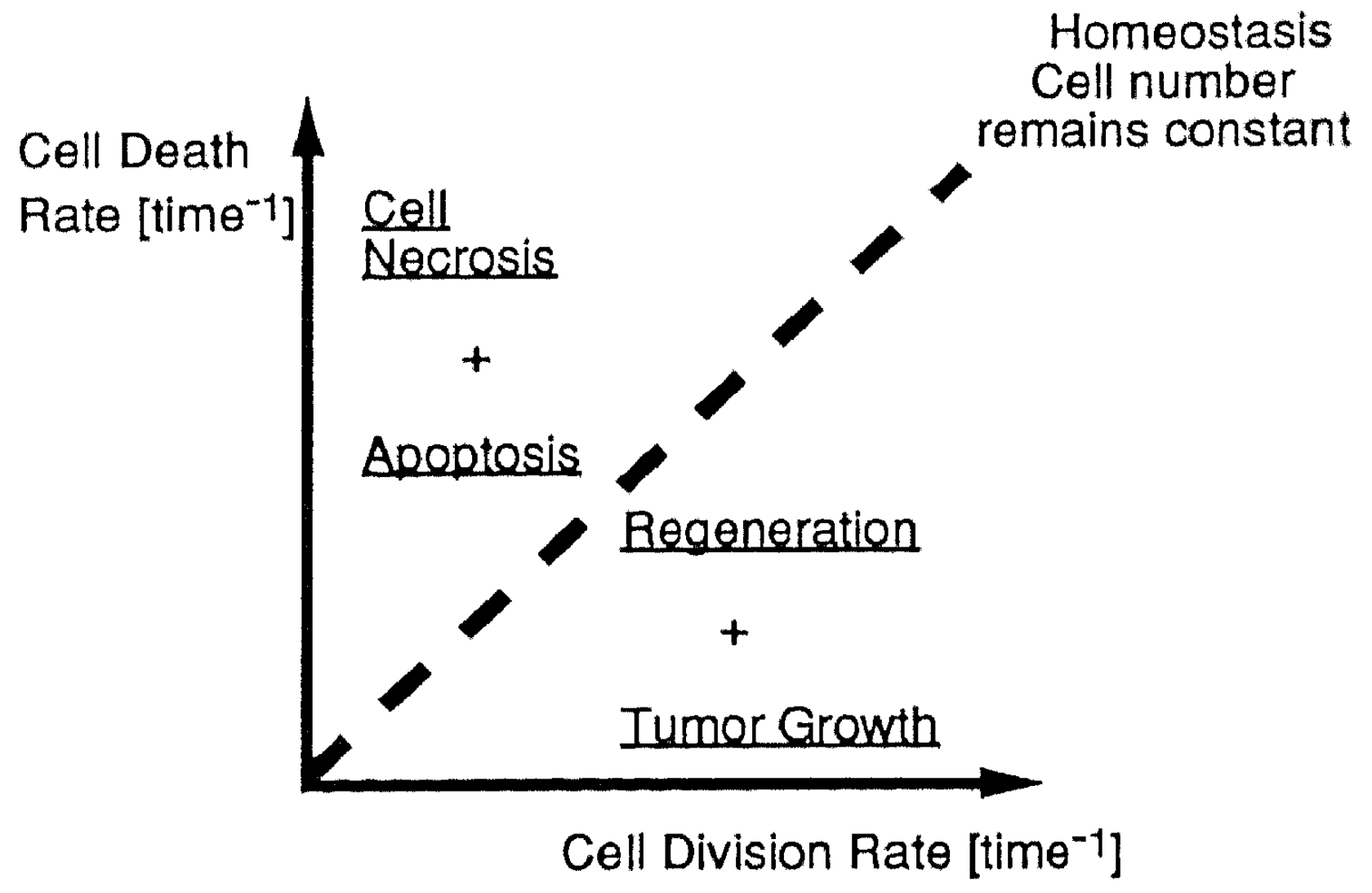

Fig. 1. Factors influencing the generation of altered cells and their propagation to preneoplastic lesions. The same factors affect the persistence of preneoplastic and neoplastic lesions and the probability of these lesions to become malignant and to metastasize 
Furthermore, susceptibility to apoptosis of individual cells of preneoplastic lesions may also depend on the cell's location within the lesions, meaning that cells located in the innermost area of the lesion would not undergo apoptosis due to the lack of available stimuli.

Zinc-NTA was demonstrated to abrogate apoptosis thus immortalizing normally senescent Syrian hamster embryo cells in culture (LeBoeuf et al. 1990). In addition to longer viability thus treated Syrian hamster embryo cells appeared phenotypically transformed. Thus, in conjunction with a wound healing process observed following NTA treatment it appears reasonable to assume that transformed renal epithelial cells could be stimulated to divide and be propagated to preneoplastic lesions and tumors. Circumstantial evidence for the existence of such a mechanism in NTA induced renal tumors is provided by the observation that after 18 months of NTA treatment followed by a 6 month NTA-free diet a high number of the early preneoplastic lesions had regressed (Alden and Kanerva 1982). This observation suggests that cessation of NTA exposure reduced cellular zinc concentrations and thus allowed the kidney to gain back control over cell cycle homeostasis and possibly to delete preneoplastic lesions via apoptosis. The late appearance of relatively small tumors i.e. following a 24 month treatment with $2 \%$ NTA in the diet as well as the rather low tumor incidence of $17 \%$ indicates that these tumors develop very slowly, which may also support the idea of a non-highly proliferative environment and thus the presence of this yet hypothetical mechanism.

\section{OTA}

The mechanism by which ochratoxin A (OTA) can induce renal tumors in rodents is still an enigma to those involved in cancer research. Although OTA was negative in all routine test systems currently used for assessment of genotoxicity, reports have come forth stating that OTA can induce DNA damage in form of single strand breaks or OTA-DNA adducts (Dirheimer and Creppy 1991; Pfohl-Leszcowicz et al. 1991). From this it would appear that the renal tumors observed in mice and rats treated with OTA can be explained by the genotoxicity of OTA. However, it has to be emphasized that OTA induced renal tumors appear only in male mice but not in female mice and at a significantly higher incidence in male than in female rats. Furthermore, the daily dose needed to induce renal tumors in male mice in a 2-year bioassay is approximately 23 -fold higher than the dose needed to induce a comparable tumor incidence in male rats. In order to characterize the tumorinduction potency of the DNA adducts found following OTA administration, these were compared to the potency of DNA adducts induced with aflatoxin $B_{1}$ in the liver of rats. $18 \mathrm{DNA}$ adducts of aflatoxin $/ 10^{7}$ nucleotides (dose: $3 \mu \mathrm{g} \mathrm{AFB}_{1} / \mathrm{kg}$ in the diet for 2 years) explain $50 \%$ of the tumors (Lutz 1986). Thus the 0.4 DNA adducts $/ 10^{7}$ nucleotides determined in renal DNA via $\mathrm{P}^{32}$ post-labelling following an i.p. dose of $2.5 \mathrm{mg}$ OTA/kg (Pfohl-Leszcowicz et al. 1991) could explain at best only 1\% of the tumors found given that a linear DNA-adduct to tumor formation relationship is applicable and only under the assumption that the OTA-adducts are as potent as aflatoxin $B_{1}$ in inducing tumors. The latter data demonstrate the discrepancy between the genotoxic potential of OTA and tumor induction, thus questioning the observation that the observed renal tumors can be explained merely by genotoxicity, especially when considering the vast sex and species differences in tumor 
susceptibility. In view of this it must be assumed that epigenetic mechanisms must play the predominant role in the aetiology of OTA induced renal tumors. Recent investigations regarding the site of OTA toxicity have shown that predominantly the pars recta proximal tubules (P3) are affected (Rasonyi et al. 1995). Increased cell exfoliation was observed in male and female rats treated with 210 and $1000 \mu \mathrm{g} \mathrm{OTA} / \mathrm{kg}$ body weight for 4 weeks. One of the striking observation was that the predominant form of cell death was apoptosis and not necrosis. Whole epithelial cells still complete with brush border were seen in the tubular lumina presenting with varying stages of apoptosis at the light as well as on the electron microscopical level. Enhanced apoptosis may result from increased calcium influx into cells, as noted earlier, OTA was shown to deregulate cellular calcium homeostasis leading to an increased intracellular calcium concentration (Rahimtula and Chong 1991), thus providing an ideal environment for activating Ca-dependent endonucleases and transglutaminases. In conjunction with enhanced apoptosis, a high number of regenerating epithelial cells as well as enlarged nuclei (karyomegaly) were observed in the most affected areas, possibly indicating genetic changes in some of these cells (Rasonyi et al. 1995). Cells with karyomegaly could potentially represent the basis for preneoplastic lesions, provided a cell proliferative stimulus can propagate these cells to such lesions. Indeed, subsequent analysis of cell replication in male and female rats treated with 70,210 , and $1000 \mu \mathrm{g}$ OTA $/ \mathrm{kg}$ body weight for 4 weeks revealed a 6-fold increase in cell proliferation in the outer stripe of the outer zone of the medulla (P3-cells), compared to the corresponding control, in either sex of the 210 and 1000 (Table 2) but not the $70 \mu \mathrm{g}$ OTA/kg groups (Rasonyi et al. 1995). These results demonstrate that a subchronic dose of 210 or $1000 \mu \mathrm{g}$ OTA/kg can induce overt cell damage and regenerative cell proliferation in rats and thus provide a basis for the development and propagation of preneoplastic and neoplastic lesions. However, the latter study demonstrates no sex differences with regard to OTA toxicity, location of effects, and regenerative cell proliferation (Table 2). Thus the question remains to be answered why female rats have an approximately 10-fold lower carcinoma incidence than male rats given the same dose $(210 \mu \mathrm{g}$ OTA/kg) in the 2 year bioassay (Boorman 1989).

Table 2. Cell proliferation ( $S$-phase labeling index (LI) in $\%$ of cells labeled) in F344 male and female rat renal pars recta proximal epithelial cells (P3) following 4 weeks continuous oral gavage with varying concentrations of OTA (from Rasonyi et al. 1995).

\begin{tabular}{|c|c|c|c|c|}
\hline$\overline{S e x}$ & $\begin{array}{l}\text { Control } \\
\text { Lu(\%) }\end{array}$ & $\begin{array}{c}70 \\
\mu \mathrm{g} \text { OTA/kg bw } \\
\text { LI }(\%)\end{array}$ & $\begin{array}{c}210 \\
\mu \mathrm{g} \text { OTA/kg bw } \\
\mathrm{LI}(\%)\end{array}$ & $\begin{array}{c}1000 \\
\mu \mathrm{g} \text { OTA/kg bw } \\
\text { LI }(\%)\end{array}$ \\
\hline $\begin{array}{l}\text { Female } \\
\text { Male }\end{array}$ & $\begin{array}{l}2.7 \pm 0.8 \\
5.2 \pm 3.2 \\
\end{array}$ & $\begin{array}{l}2.0 \pm 0.3 \\
3.2 \pm 2.3 \\
\end{array}$ & $\begin{array}{r}30.5 \pm 9.0 \\
25.9 \pm 10.3 \\
\end{array}$ & $\begin{array}{r}38.8 \pm 8.4 \\
38.3 \pm 4.6 \\
\end{array}$ \\
\hline
\end{tabular}

Several possibilities can be imagined as to how this sex difference in tumor susceptibility can come about. One may be that female and male rats produce a different number of DNA adducts or adducts at a different genetic location leading to more serious genetic damage in the case of male rats. However, based on the fact that most DNA adduct studies have been conducted in male rats and mice and that only a negligible number of tumors can be explained with genotoxicity, this hypothesis seems a bit weak. Another may be that the cell proliferative response may 
ablate in female rats during chronic administration of OTA, whereas the cell proliferative stimulus might even increase in ageing male rats with the onset of chronic progressive nephropathy often observed to be more pronounced in male rats than in female rats (Dietrich and Swenberg 1991b). Studies looking at the chronic effect of OTA administration on cell proliferation, persistence of DNA adducts and formation of preneoplastic lesions in both sexes of rats are yet missing. With regard to tumor induction in mice and rats, the above data suggest that either the mechanism of OTA tumor induction is completely different in rats than in mice or that mice are much less susceptible to OTA than rats, thus questioning the extrapolatability of such data for human risk assessment without detailed knowledge of the mechanisms involved.

\section{Types of preneoplastic lesions induced by non-genotoxic carcinogens}

Sequential observations on the appearance of neoplastic lesions in rats and mice treated with alkylating agents, e.g. EHEN, Dimethylnitrosamine, Diethylnitrosamine, and N-Nitrosomorpholine led to the discovery of early lesions that shared morphological characteristics with renal cell tumors and to the identification of at least five different cell types, i.e. clear, acidophilic, basophilic, chromophobic, and oncocytic cells (Bannasch and Zerban 1990; Dietrich and Swenberg 1991b; Dietrich and Swenberg 1991c). Interestingly similar lesions and cell types were observed in rodents treated with non-genotoxic carcinogens such as d-limonene, NTA and OTA (Dietrich and Swenberg 1991b; Dietrich and Swenberg 1993). Furthermore, the presence of comparable cell types and tumors in humans (Stoerkel 1993) holds promise that the aetiology of renal tumors can be studied using the rodent as a surrogate. However, it is important to note that there is quite a discrepancy with regard to the predominance of tumor types in rodents and humans. While clear cell atypical tubules, atypical hyperplasias and tumors have been observed in rodent kidneys following treatment with alkylating agents, clear cell preneoplastic lesions but no clear cell tumors are reported in rodents treated with d-limonene, OTA or NTA. Indeed, clear cell lesions appear to change with increasing progression to either acidophilic and/or basophilic tumors as primarily basophilic tumors are reported in studies with OTA, NTA and d-limonene. Whether this morphological and biochemical change represents additional mutations that have been incurred during progression is a this point not clear. However, it is interesting to note that clear cell preneoplastic lesions induced with alkylating agents can persist and progress to veritable clear cell tumors (Dietrich and Swenberg 1991c), demonstrating that the morphological appearance does not give any indication of the genetic change that has occurred. Thus the morphological appearance of a preneoplastic lesion a priori does not allow deduction of the progressiveness and tendency for malignant conversion of the lesion. The rate of lesion growth and thus persistence and progression is not only determined by the genetic changes the clones have undergone, but is also a function of the proliferative potential of the individual lesions, i.e. the product of clone proliferation and susceptibility for clone necrosis/apoptosis and differentiation (Fig. 1), as well as of the environment of the lesion. The environment may allow the lesion to grow due to toxicant mediated chronic stimulation of cell proliferation (d-limonene and OTA) or abrogation of apoptosis (NTA). Thus, in order to characterize the aggressiveness of a preneoplastic lesion it would be 
necessary to determine its net growth. Although important, such studies are currenty missing in rodent renal carcinogenesis. In contrast to tumors in the rodent where mostly basophilic and acidophilic adenomas, carcinomas and metastatic carcinomas are observed, e.g. OTA induced renal cell carcinomas, the predominant type of renal cell tumor in humans is the clear cell tumor with an incidence of $76 \%$ of renal tumors registered (Thoenes and Stoerkel 1991). This type of tumor also has the worst prognosis of the renal cell tumor types. This raises the question whether the aetiology of renal tumors in rodents is really comparable to the one in humans. especially considering the fact that the tumor cell type in rodents appears to be highly dependent on the carcinogenic agent, whereas the cause(s) for most human tumors is currently unknown. Furthermore, due to the late detection of renal tumors in humans it is virtually impossible to study the behaviour of preneoplastic lesions in humans and to compare these to those in rodents.

\section{Conclusions}

The mechanisms associated with the formation of preneoplastic and neoplastic lesions by non-genotoxic agents are known but for one group of compounds, namely those inducing $\alpha 2 \mu$-globulin nephropathy. Due to the exclusive male rat specificity of $\alpha 2 \mu$-globulin nephropathy, this mechanism is not extrapolatable for risk assessment to the human situation. The knowledge gained by studying the development of preneoplastic lesions induced by this mechanism, however, made it possible to understand how enhanced cell proliferation can provide a basis for renal tumor formation. Although viable hypotheses have been put forward as to the mechanisms involved in NTA and OTA induced renal tumors, the paucity of mechanistic data presently available make these hypotheses pure speculation. However, despite the above caveats it is possible to characterize the aetiology of renal tumors by studying the formation and behaviour of preneoplastic lesions, whether induced by genotoxic or non-genotoxic agents.

\section{Acknowledgements}

We would like to thank Regula Candrian for her magnificient help in the laboratory experiments as well as to extend our gratitude to Prof. Fritz Würgler, Prof. Werner Lutz, and PD Dr. Urs Bolsterli for critically reading this manuscript. Part of these studies were funded by BASF, Ludwigshafen FRG and by the Swiss Federal Office of Public Health (BAG) grant No. (FE 316 91-343).

\section{References}

Alden CL, Kanerva RL (1982) Reversibility of renal cortical lesions induced in rats by high doses of nitrilotriacetate in chronic feeding studies. Fd Chem Tox 20:935-937

Alden CL, Kanerva RL, Anderson RL, Adkins AG (1981) Short-term effects of dietary nitrilotriacetic acid in the male Charles River rat kidney. Vet Path 18: 549-559

Anderson RL (1981) The role of zinc in nitrilotriacetate (NTA) associated renal tubular cell toxicity. Fd Cosmet Toxicol 19:639-650 
Anderson RL, Bishop WE, Campbell RL (1985) A review of the environmental and mammalian toxicology of nitrilotriacetic acid. CRC Crit Rev Toxicol 15(1):1-102

Bannasch P, Zerban H (1990) Animal models and renal carcinogenesis. In: Eble JN (ed) Contemporary issues of surgical pathology. New York, Churchill Livingstone. pp 1-34

Barrett JC, Wiseman RW (1987) Cellular and molecular mechanisms of multistep carcinogenesis: relevance to carcinogenic risk assessment. Environ Health Persp 76:6570

Boorman G. (1989) Toxicology and carcinogenesis studies of ochratoxin A in F344/N rats. National Toxicology Program, Technical Report Series No. 358

Borghoff SJ, Short BG, Swenberg JA (1990) Biochemical mechanisms and pathobiology of alpha 2u-globulin nephropathy. Annu Rev Pharmacol Toxicol 30:349-67

Büsselberg D, Evans ML, Rahman H, Carpenter DO (1990) Zn2+ blocks the voltage activated calcium current of Aplysia neurons. Neuroscience Lett 117:117-122

Cerutti PA (1988) Commentary. Response modification creates promotability in multistage carcinogenesis. Carcinogenesis 9:519-526

Croce CM, Klein G (1990) Chromosomal-translocation and cancer. In: Schirrmacher V (ed) Cancer-Tumors, Cells, Genes. Heidelberg, Scientific American pp 102-109

Dietrich DR (1994) Alpha 2 $\mu$-Globulin: Species and sex specific protein synthesis and excretion and its association with chemically induced renal toxicity and neoplasia in the male rat, and its relevance in conjunction with human cancer risk assessment. Rev Biochem Toxicol 13:in press

Dietrich DR, Swenberg JA (1991a) NCI-Black-Reiter (NBR) male rats fail to develop renal disease following exposure to agents that induce alpha-2u-globulin (alpha 2u) nephropathy. Fundam Appl Toxicol 16(4):749-62

Dietrich DR, Swenberg JA (1991b) Preneoplastic lesions in rodent kidney induced spontaneously or by non-genotoxic agents: predictive nature and comparison to lesions induced by genotoxic carcinogens. Mut Res 248: 239-260

Dietrich DR, Swenberg JA (1991c) The presence of alpha 2u-globulin is necessary for dlimonene promotion of male rat kidney tumors. Cancer Res 51(13):3512-3521

Dietrich DR, Swenberg JA (1993) Renal carcinogenesis. In: Hook JB, Goldstein RS (eds) Toxicology of the Kidney. New York, Raven Press pp 495-537

Dirheimer G, Creppy EE (1991) Mechanism of action of ochratoxin A. In: Castergnaro M, Plestina R, Dirheimer G, Chernozemsky IM, Bartsch H (eds) Mycotoxins, Endemic Nephropathy and Urinary tract tumors. Lyon, International Agency for Research on Cancer, IARC. pp 171-186

Farber E, Sarma DRS (1987) Hepatocarcinogenesis: a dynamic cellular perspective. Lab Invest 56:4-22

Knudson AGJr (1987) A two-mutational model for human cancer. In: Klein G (ed) Advances in Viral Oncology. New York, Raven Press 1-17

Lane DP (1993) A death in the life of p53. Nature 362:786-787

LeBoeuf RA, Kerckaert GA, Aardema MJ, Poiley JA, Raineri R (1990) Enhanced morphological and neoplastic transformation of syrian hamster embryo cells cultured at pH 6.70. In: Mendelsohn ML, Albertini RJ (eds) Mutation and the Environment: Part D: Carcinogenesis. New York, Wiley-Lyss pp 219-228

Loeb LA (1989) Endogenous carcinogenesis: molecular oncology into the twenty-first century - Presidential Address. Cancer Res 49:5489-5496

Lutz WK (1986) Quantitative evaluation of DNA binding data for risk estimation and for classification of direct and indirect carcinogens. J Cancer Res Clin Oncol 112:85-91

Lutz WK (1990) Endogenous genotoxic agents and processes as a basis of spontaneous carcinogenesis. Mut Res 238:287-295

Martin SJ, Cotter TG (1994) Apoptosis of human leukemia: Induction, morphology, and molecular mechanisms. In: Tomei LD, Cope FO (eds) Apoptosis II: The molecular basis of apoptosis in disease. Cold Spring Harbor, Cold Spring Harbor Press pp 185229 
Martin SJ, Green DR, Cotter TG (1994) Dicing with death: dissecting the components of the apoptosis machinery. Trends in Biol Sci 19:26-30

Mills JW, Zhou J-H, Cardoza L, Ferm VH (1992) Zinc alters actin filaments in Madin-Darby canine kidney cells. Toxicol Appl Pharmacol 116:92-100

Peitsch MC, Mannherz HG, Tschopp J (1994) The apoptosis endonucleases: cleaning up after cell death. Trends in Cell Biol 4:37-41

Pfohl-Leszcowicz A, Chakor K, Creppy EE, Dirheimer G (1991). DNA adduct formation in mice treated with ochratoxin A. In: Castergnaro $M$, Plestina $R$, Dirheimer $G$, Chernozemsky IM, Bartsch H (eds) Mycotoxins, Endemic Nephropathy and Urinary tract tumors. Lyon, International Agency for Research on Cancer, IARC pp 245-253

Pitot HC (1986) The natural history of neoplastic development: Initiation and Promotion. In: Pitot HC (ed) Fundamentals of Oncology. New York, Marcel Dekker Inc

Rahimtula AD, Chong X (1991) Alterations in calcium homeostasis as a possible cause of ochratoxin A nephrotoxicity. In: Castergnaro $M$, Plestina $R$, Dirheimer $G$. Chernozemsky IM, Bartsch H (eds) Mycotoxins, Endemic Nephropathy and Urinary Tract Tumors. Lyon, International Agency for Research on Cancer, IARC pp 207-214

Rasonyi T, Dietrich DR, Schlatter J, Schlatter C (1995) Site specific toxicity and regenerative cell proliferation in male and female F344 rats treated for 4 weeks with different doses of ochratoxin A. Fundam Appl Toxicol; in preparation

Rivera Torres MI, Caudill D, Lehman-McKeeman LD (1989) Lysosomal degradation of alpha2u-globulin (A2u): Role of cysteine and aspartic acid proteinases and effects of dlimonene binding. Toxicologist $9(1) \div 314$

Short BG, Burnett VL, Swenberg JA (1989) Elevated proliferation of proximal tubule cells and localization of accumulated alpha $2 \mathrm{u}$-globulin in F344 rats during chronic exposure to unleaded gasoline or 2,2,4-trimethylpentane. Toxicol Appl Pharmacol 101(3):414-31

Short BG, Steinhagen WH, Swenberg JA (1989) Promoting effects of unleaded gasoline and 2,2,4-trimethylpentane on the development of atypical cell foci and renal tubular cell tumors in rats exposed to $\mathrm{N}$-ethyl-N-hydroxyethylnitrosamine. Cancer Res 49(22):6369-6378

Stevens JL, Jones TW (1990) The role of damage and proliferation in renal carcinogenesis. Toxicol Lett 53:121-126

Stoerkel S (1993) Carcinomas and oncocytomas of the kidney. In: Denk H, Dietel M, Fischer R, Hoefler H, Katenkamp D, Seifert G, Dhom G, Eder M, Heitz PU, Holzner H, Lennert K, Thoenes W (eds) Progress in Pathology. New York, Gustav Fischer Verlag pp 164

Swenberg JA, Richardson FC, Boucheron JA, Deal FH, Belinsky SA, Charbonneau M, Short BG (1987) High- to low-dose extrapolation: Critical determinants involved in the dose response of carcinogenic substances. Environ Health Persp 76:57-63

Swenberg JA, Short BG (1987) Influence of cytotoxicity on the induction of tumors. In: Butterworth BE, Slaga TJ (eds) Nongenotoxic mechanisms in carcinogenesis. Cold Spring Harbor, NY, Cold Spring Harbor Laboratory pp 151-161

Thoenes W, Stoerkel S (1991) Die Pathologie der benignen und malignen Nierenzelltumoren." Urologe-A 30:W41-W50 